Case Report

\title{
LIVED EXPERIENCES OF MOTHERS OF CHILDREN WITH DOWN'S SYNDROME IN SELECTED SCHOOLS AT MANGALORE
}

\author{
Reeja M ol $\mathbf{R}^{1} \&$ Sujatha $\mathbf{R}^{2}$ \\ ${ }^{1}$ M .Sc. (N) Student, ${ }^{2}$ Professor \& HOD, Department of Child Health Nursing, \\ Nitte Usha Institute of Nursing Sciences, Nitte University, Kotekar Beeri Road, Paneer, Deralakatte, \\ M angalore - 575 018, Karnataka, India \\ Correspondence \\ Sujatha $\mathbf{R}$. \\ Professor \& HOD, Department of Child Health Nursing, \\ Nitte Usha Institute of Nursing Sciences, Nitte University, Mangalore- 575 018, India \\ E-mail : sujathakannappan@gmail.com
}

\begin{abstract}
:
This qualitative study explored the mother's experiences of parenting a child with Down's syndrome. The research approach used in this study was Phenomenology. Interviews were conducted with seven mothers who had a child with Down syndrome. The study was conducted at selected special schools at M angalore. From the Analysis of the data six major themes were emerged. Non acceptance Birth of an abnormal child, Lifestyle changes, High bonding between family members, Worried about the unpredictable future of the child, Societal and Community acceptance and Positiveness towards life. These findings show that birth of a child with Down syndrome produces tremendous physical and psychological effect in parents. So parents need adequate support from nurses right from the very birth of a disabled child. Therefore this study is important for nurses working with families having children with Down syndrome. They need to realize and aware of the problems faced by the families and should advocatenecessary support.
\end{abstract}

Keywords: Phenomenology, lived experiences, Down's syndrome

\section{Introduction :}

Having a child with Down's syndrome leads to changes in the lifestyle of the whole family. Identification and acceptance of learning disabilities are difficult processes, and promoting the child's optimal development require adaptation by all family members, whose characteristics, as well as the degree of affiliation and support among them, have great influence on these lifestyle changes, both in terms of quality and quantity.

Parents play a vital role in caring for and rearing their children - even more so if it is a child with Down's syndrome. Parents react differently to their child's impairment. Gallagher Access this article online Quick Response Code

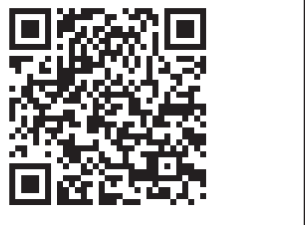
says some parents will accept the impairment more easily than others and will carry out the task of caring for the child more cheerfully with greater devotion. However, others feel isolated and distressed and may experience chronic sorrowfulness. Steenkamp states that there is no typical reaction to the birth of a disabled child.

Many families in today's society almost idolize their children, the children who carry their parents' hopes and dreams. Donahoo (2007) noted: "Of course, creating the perfect child or perfect childhood is impossible, but that has not stopped us from expending tremendous amounts of energy trying". He described the phenomenon as arising from social and economic factors, such as more money and more competition, to the point where children have become the latest status symbol for some parents. Within this context, life with a child with disabilities gives parents unique experiences, with unique joys and difficulties.

Although many very young women continue to have children and a large group of parents have waited to start a family until they are settled in their lives, perhaps seeing their baby as a culmination of all their dreams. Babies often become the center of the parents' lives, energy, money and socialization. It can be, as Landsman (2009) said, "an age in 
which infants are commodified and technology seems to hold out the promise of perfect babies".

M ost of the research studies on the experiences of families who have a child with a disability indicate that, although there may be commonalities in the parenting experiences, the impact differs considerably among families (Bower et al., 1998; Hanson, 2003; M uscott, 2001). In a meta-analysis since 1975, that examined marital strain in families who had a child with a disability, Risdal and Singer (2004) reported that although there was a negative impact, the effect was much smaller than expected. Bower et al. (1998) found in their research that the presence of a child with Down syndrome can no longer be seen as a universal catalyst for family difficulties or family dysfunction. They suggested that the ideas and beliefs of family members, including the extended family, need to be understood in order to appreciate how families cope with the challenges of parenting a child with a disability. However, a family may also require different levels of support to manage the demands required by specific health, behavioral and education needs of their child for whom they have little knowledge or experience.

\section{Materials And Methods:}

The research approach used in this study was Phenomenology. Seven mothers of children with Down's syndrome who met the inclusion criteria were selected using purposive sampling technique from the selected special schools at M angalore.

The researcher contacted the mothers and explained the purpose of the study. The investigator prepared them for the actual meeting before the interview to answer any preliminary questions. At the time of the first interview the researcher obtained informed consent and permission to tape record the conversation. The interview was conducted during their next visit in the special school. In depth interviews were conducted in a selected room in the special school with all privacy. The interviews were started with open ended clarifying questions like "Would you share with me your responses when you heard that your child is having Down's syndrome." Each tape recorded interviews

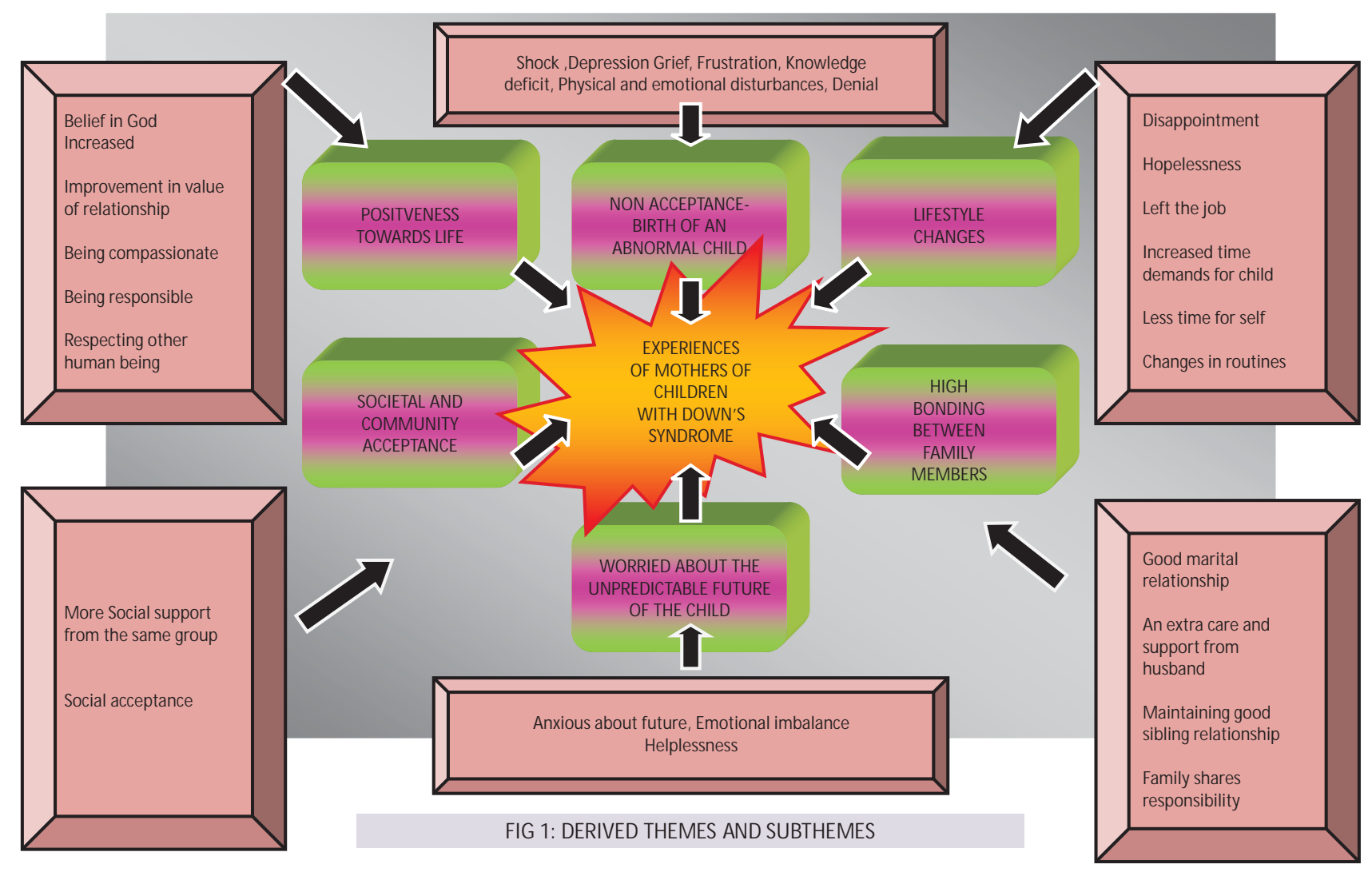


lasted approximately 30 to 45 minutes. The language of communication was M alayalam and English.

\section{Results :}

Colaizzi's data analysis framework was used to analyze the transcripts in this study. From the analysis of the data, six themes emerged from the experiences of mothers of children with Down's syndrome and they were as follows: (Refer fig.2)

Theme 1: Non acceptance - Birth of an abnormal child

Theme 2: Lifestyle changes

Theme 3: High bonding between family members

Theme 4: Worried about the unpredictable future of the Child

Theme 5: Societal and Community acceptance

Theme 6: Positiveness towards life

\section{Discussion :}

From the analysis of the data, six themes were emerged from the experiences of mothers of children with Down syndrome.

\section{Theme 1: Non Acceptance - birth Of An Abnormal Child.}

The first theme was Non acceptance - Birth of an abnormal child. All the participants expressed their feelings of shock and depression at the moment they came to know that their child is having Down syndrome also they were anxious about their child condition .One mother expressed she doesn't know how to take care of the child.

"I am really shocked"...

I am depressed so much. I had no idea what Down syndrome was but I knew that it's something that is not normal... (Participant 2)

"Actually I cannot believe I thought it is like normal only. I prayed to God nothing should be happened. I had no idea how to take care of my child. I was anxious..." (Participant 4)

This referred to mothers' insufficient knowledge regarding the diagnosis of Down syndrome and the care of a child with this syndrome. M ost mothers had no idea what Down syndrome was, and some related the syndrome to mental illness. Several mothers said that they doubted the diagnosis. Their initial reaction after discovering the child has Down's syndrome is shock and disbelief followed by anger, disappointment, denial and often guilt feelings.

Carswell and Grossi stated that the birth of a child with Down syndrome may result in psychological pain for their parents. This psychological impact is responsible for generating confused feelings that may persist throughout life. So Parents need adequate support right from the very birth of a disabled child.

A qualitative study was conducted by Elaine Herbert of Parents' reported responses to the disclosure of Down syndrome. The mothers exhibited a wide range of strong emotions; in two cases the mothers became so upset it was not possible to complete the schedule. The mothers' descriptions highlighted feelings of 'chronic sorrow' (Olshansky, 1961; Wikler, 1984) and that the birth of their children had set them apart from other mothers.

The way in which parents are informed about their child's condition often has a profound effect on them .There is a clear relationship between the way in which parents are informed of their child's disability and their initial reaction and acceptance of the news. Parents are often not familiar with the medical terms used to describe the child's condition to them. They need a truthful and simple explanation of the diagnosis, the child's prognosis and available services and Intervention programs.

\section{Theme 2: Lifestyle Changes}

The second theme was lifestyle changes. After the child's birth, the immediate stressor mothers encountered was facing a child who was completely different from their expectations. M ost stressful was that the child had Down syndrome and it was not curable. All the participants' expectations are changed after the child was diagnosed with Down syndrome. Most of the mothers expressed as they need to spend more time with the child.

"No one will expect rather than a normal baby. Now for every work he wants help from us. So I need to spend more time with him...I left my job after my child birth" (participant 3) 
Heller et al. found that in comparison with fathers of intellectually disabled children, mothers spent more time providing care, offered more types of support and perceived more care giving burden. The behavior and health of the children had a greater impact on mothers than on fathers. One mother expressed she doesn't know about Down syndrome. Another mother expressed as she had lot of dreams about her child. But all the dreams were shattered when child was diagnosed with Down syndrome.

A qualitative study was conducted by Janet M olzan Turan on experiences and lifestyles of families in Turkey with children with Down syndrome, including the impact on family members. Twelve mothers with a Down syndrome child participated and data were collected during in-depth interviews and were evaluated using qualitative data analysis methods. Families were affected socially, physically, economically and emotionally by having a child with Down syndrome.

When raising a disabled child every parent experienced the situation as more demanding and complex. Parents need to have support and counseling available to them as soon as possible after the birth of a disabled child. Professional counseling will help parents to understand the process through which they are going, assist them in analyzing what is happening to them and provide them with coping strategies.When parents encounter difficulties in meeting the special needs of the disabled child, they are likely to search for appropriate services and helpful professionals.

\section{Theme 3: High Bonding Between Family Members.}

The third theme was high bonding between family members. Every mother expressed they are maintaining good relationship with family members. Most of the mothers expressed as husband is most supportive person in caring children with Down syndrome.

"In my family my husband is supportive. He gives so much care to the child. He always has a loving mind. Sometime I feel my child is normal, because he used to teach so many rhymes to my younger son. They play together, also they fight together". (Participant 1)
All mothers said that the siblings accepted their child with Down syndrome. One mother expressed her elder son takes care of his little brother with Down syndrome.

"I am really happy because my husband is the most supportive person. Now my child has 10 years and elder son has 17 years. So he takes care of his little brother and they are loving each other" (Participant3)

Pearson and Stemberg reported that siblings were very protective of a child with a developmental delay and would undertake care responsibilities as well as protecting and defending the disabled child.

A study was done to explore how children respond to the experience of living in a family that includes a child with Down syndrome. The results indicate that for many siblings, the experience of living in a family that includes a child with Down syndrome may be a positive, growth producing experience. In addition maternal reports typically indicated that these siblings were socially competent, with a low incidence of behavior problems.

Marcia van Riper stated when parents were asked to describe how well their family was doing, most reported that their family was doing well to very well. M any noted that they were doing much better than they had originally predicted. It indicates that while the birth of a child with Down syndrome involves a 'change of plans' for families, it does not have to be a negative experience. In fact for many it is a positive, growth producing experience.

Family Support is essential for the mothers of children with disabilities. Coping with the stress, emotions and difficult decisions is often overwhelming and upsetting for families. Support groups, educational seminars and facilitated families meetings can be very helpful and productive to the planning process.

\section{Theme 4: Worried About the Unpredictable Future of the Child.}

The fourth theme was worried about the unpredictable future of the child. This referred to mothers worry about their child in the near and distant future. Immediate 
worries were the child's school placement and health status. Looking farther ahead, mothers' major worries concerned the child's self-caring ability, the ability to make a living and become independent. M ost of the participants have worried about whether their child will be able to take care of him or herself in later years. One mother said that she worries if her child will be able to go school will make friends and will be able to get married. All of the mothers agreed that they are anxious about "who will look after their child after their death".

“Now we are leading normal life only, but when think about the future am really sad. M ost of the time I will think who take care of our child after our death."(Participant 5)

"Sometimes in this school I come across mothers who are very old but still have to take along with them a grown-up adult of this kind.... Before coming this school l am anxious about whether he will be able to go school will make friends". (Participant 6)

A qualitative study was conducted by Graungaard, A. H. and Skov $L$ of parents' experiences, coping and needs, when the newborn child is severely disabled Child. Results show the certainty of the diagnosis was central for parents' experiences. First, the emotional reaction of the parents is highly influenced by the diagnostic process and second they found difficulty in coping with an uncertain future.

It can be a very difficult and uncertain time for families who have just found out that their baby has Down syndrome. There can be a lot of questions, concerns and fears about the future. So adequate support group and other helpline should be provided for families of children with disabled.

\section{Theme 5: Societal And Community Acceptance}

The fifth theme was societal and community acceptance. M ost of the mothers expressed they got adequate support from society. All the mothers placed an emphasis on the importance of social support from outside the family.

"Society is treating them very well. In our family he is very active. He engages in every activity especially in sports. Everyone in the society cares my child well. So I didn't felt any social restrictions because of my child. Wherever I go my child is with me. Whenever I am attending any function also my child stays with me. So I am really happy." (Participant 1)

A phenomenological study conducted by Esther Joosa and Donna Berthelsen on mothers experiences of parenting a child with Down syndrome. The themes were found in the data are a child with Down syndrome -impact, social and formal support and societal and community acceptance.

A study conducted by Lily L Dyson of Fathers and M others of School-Age Children with Developmental Disabilities: Parental Stress, Family Functioning, and Social Support. Thirty pairs of fathers and mothers who had school-age children with mental retardation and other disabilities were compared with each other and with 32 pairs of fathers and mothers of children without disabilities. Responses to family scales indicated that fathers and mothers of children with developmental disabilities did not differ from each other nor from fathers and mothers of children without disabilities in parental stress, family social support, or family functioning. However, parents of children with disabilities experienced a disproportionately greater level of stress relating to their children than did those of children without disabilities.

Majority of studies have suggested various supports and coping strategies that are effective for adapting with the situation. There is evidence that support by friends, relatives, and health care professionals play an important role in assisting mothers in their role as a parent of child with disability.

Van Riper found that maternal well-being and mothers' perceptions of family functioning were associated with their perceptions of the quality of the support they received from the professionals working with them and their child with Down syndrome. Other family members particularly grandparents, play a central supporting role for many families.

\section{Theme 6: Positiveness Towards Life.}

The sixth theme was Positiveness towards life. All the 
participants expressed their changes in way of living after the birth of Down syndrome child. One mother said that her entire family and marital life is stronger also they become closer to God and started to accept others.

"Our entire family and marital life is stronger. It has changed our view of the world, our view of ourselves and others .It has made us more giving and less selfish. It has drawn us closer to God .It has caused us to be more concerned about others who are different. It has shown us what we value in life...relationships... not power and wealth". (Participant2)

A study was conducted by Evelyn M. Flaherty \& Laraine M asters Glidden of Positive Adjustment in Parents Rearing Children with Down syndrome. Overall, birth as well as adoptive, families appeared to be adjusting well to the challenges of rearing a child with Down syndrome.

A study was conducted by B. Ryde-Brandt of M others of primary school children with Down's syndrome. The results indicated that negative feelings at the birth of a child with DShad almost invariably changed in a positive direction.

A study was conducted by Marcia van Riper on parental responses to the birth of child with Down syndrome. All parents reported that the experience of raising a child with Down syndrome had a profound impact on their life. Positive consequences include; bringing the family closer together, learning the true meaning of unconditional love, putting things in proper perspective and appreciating diversity.

Poehlmann and colleagues found that mothers saw their child with Down syndrome as having a number of very positive personal characteristics that acted to maintain and develop connections between family members and with others. Hodapp, Fidler and Ricci found no difference between parents of a child with Down syndrome and parents of typically developing children with respect to 'rewardingness'. Cuskelly and colleagues found that mothers of a child with Down syndrome reported significantly more reinforcing aspects of their relationship with their child than did mothers of typically developing children.

\section{Conclusion}

Therefore the findings of this study is important for nurses working with families having children with Down syndrome children need to be aware of the problems faced and should advocate for necessary support. Nurses can play an important role in helping the parents to deal with the difficulties of child with disabilities. They can educate them on many topics ranging from basic care requirements to supporting the family in making arrangements that will help the child to take care of him or herself. Nurses can promote parents' coping strategies in managing children with disabled.

\section{Acknowledgements:}

It is my pleasure and privilege to record my deep sense of gratitude to all who have contributed to the accomplishment of this effort especially Nitte University, Prof.Fathima D'Silva the Principal, NUINS for her valuable guidance, my guide Prof. (Mrs.) Sujatha.R, Dept of Child Health Nursing for her inspiring guidance, valuable suggestions, timely advice, constant encouragement and support for the completion of this study. I am deeply indebted to my beloved parents. I owe my success to them who made this task possible through their constant prayers, unconditional support and encouragement.

\section{References:}

1. Polit DF, Beck CT. Nursing Research: Principles and M ethods. 7th edition. Philadelphia: Williams and Wilkims; 2004

2. MaCnee C, McCabe S. Understanding Nursing Research. 2nd ed. Philadelphia: Lippincott Williams and Wilkins; 2008

3. Davies, D., \& Dodd, J. Qualitative research and the question of rigor. Qualitative Health research, Vol 12(2), 2002. P 279-289

4. Eisner, E. W. The enlightened eye: Qualitative inquiry and the enhancement of educational practice. New York, NY: Macmillan Publishing Company; 1991

5. Helen j.Streubert Speziale, Dona Rinaldi Carpenter,'Qualitative Research In Nursing' $4^{\text {th }}$ edition, Lippincott Williams and Wilkins publishers, Philadelphia

6. Stenbacka, C. Qualitative research requires quality concepts of its own. M anagement Decision, 39(7), 2001. P 551-555

7. John L. Sanders \& Sam B. M organ(2008) Family Stress and Adjustment as Perceived by Parents of Children with Autism or Down syndrome. Child Family Behavior Therapy (2001) Volume: 23, Issue: 4, Publisher: Taylor \& Francis Group, Pages: 1-20 available from http://www. mendeley.com/catalog/child-family-behavior-therapy-family-stressadjustment-perceived-parents-children-autism-down-syndro/

8. Evelyn M. Flaherty \& Laraine Masters Glidden(2007) of Positive Adjustment in Parents Rearing Children with Down syndrome. Early Education \& Development, Volume11,Issue 4, 2000. Available from http://www.tandfonline.com/doi/abs/10. 